\title{
Online Identification Methods of Load Rotary Inertia and Torque in Radar Servo System
}

\author{
Yong Chen, ${ }^{1}$ Xia Liu, ${ }^{2}$ and Hu Zhou ${ }^{1,3}$ \\ ${ }^{1}$ School of Energy Science and Engineering, University of Electronic Science and Technology of China, Sichuan 611731, China \\ ${ }^{2}$ School of Electrical and Information Engineering, Xihua University, Sichuan 610039, China \\ ${ }^{3}$ Dongfang Electric Corporation DEC R\&D Centre, Sichuan 611731, China \\ Correspondence should be addressed to Yong Chen; ychencd@uestc.edu.cn
}

Received 27 September 2014; Revised 9 December 2014; Accepted 10 December 2014; Published 31 December 2014

Academic Editor: Xinkai Chen

Copyright (C) 2014 Yong Chen et al. This is an open access article distributed under the Creative Commons Attribution License, which permits unrestricted use, distribution, and reproduction in any medium, provided the original work is properly cited.

\begin{abstract}
In radar servo system, the load is usually subject to movement and gust, which may cause instability of the system. In this paper, the online identification methods of load rotary inertia and torque in radar servo system are proposed, respectively. The radar servo system is based on synchronous motor. The load rotary inertia of the system is identified online by a disturbance observer. Moreover, a reduced order Luenberger observer is designed to observe the variation of the load torque and velocity online. The simulation models are established to verify the proposed disturbance observer for the load rotary inertia and the reduced order Luenberger observer for the load torque and velocity.
\end{abstract}

\section{Introduction}

In radar servo system, the revolution of the load is usually subject to movement and gust, which may cause instability of the load rotary inertia and torque. Therefore, the stability of the servo controller is facing higher requirements. If the parameters of the controller in the speed loop do not match the load rotary inertia, the dynamic response of the system may become slow and even cause oscillation [1]. Furthermore, the load torque is also subject to the disturbance of gust torque. In some cases, the value of the gust torque is very big and uncertain. As a result, the descent of the revolution speed at the transient state in the radar system is big and thus the target tracking is adversely affected [2]. In order to enhance the dynamic and static characteristics and the disturbance rejection ability of radar servo system, online identification of the load rotary inertia and torque is a premise [3].

As for the research on the online identification of load rotary inertia, a speed response method for AC servo system was proposed in [4]. By modifying the output current limitation value of the speed controller, the speed response value and response time under different current limitation values are obtained, and then the rotary inertia is calculated.
This method may affect the normal operation of the motor in practice and is not applicable to identify the rotary inertia online. In addition, a model reference adaptive method for permanent magnet synchronous motor (PMSM) was presented in [5] to estimate the rotary inertia. However, both the speed response method and the model reference adaptive method neglect the effect of the viscous friction of the rotor. Comparatively, the online identification method of the rotary inertia based on disturbance observer (DOB) considers the external disturbance and friction, respectively $[6,7]$. More methods on load torque and speed are extended Kalman filters for PM synchronous motors [8], recursive input estimation for PMSM [9], and robust estimation based on singular perturbation theory [10]. Besides, disturbance is regarded as a constant or function in some papers [10, 11]. Nevertheless, the load torque in radar servo system is usually subject to the effects of gust and environment that are difficult to be defined as some noise in analysis. Therefore, it is necessary to propose an effective algorithm to directly identify the load torque and speed online. In this paper, according to the characteristics of radar servo system, a more practical online identification algorithm of rotary inertia based on DOB is proposed. The external disturbance and 
the friction of the model are estimated by the designed $\mathrm{DOB}$ and then the rotary inertia is identified. As far as the research on load torque and speed is concerned, Luenberger state observer can be employed to estimate the disturbance torque and a reduced order Luenberger load torque observer is designed to overcome the randomness of the disturbance torque.

This paper is organized as follows. In Section 2, motion equations of servo system are built. In Section 3, the load rotary inertia is identified online by a DOB. Then, a reduced order Luenberger observer is designed to observe the variation of the load torque in Section 4. In Section 5, the simulation models are established, and the DOB for the load rotary inertia and the reduced order Luenberger observer for the load torque are verified by simulations, respectively, in Section 6. Finally, this paper is concluded in Section 7.

\section{Motion Equations of Servo System}

In $d q$-frame, the mathematical model of PMSM can be expressed as follows [1]:

$$
\begin{gathered}
u_{d}=R i_{d}+L_{d} p i_{d}-\omega_{m} L_{q} i_{q}, \\
u_{q}=R i_{q}+L_{q} P i_{q}+\omega_{m} L_{d} i_{d}+\omega_{m} \psi_{f} .
\end{gathered}
$$

The electromagnetic torque is given as

$$
T_{e}=\frac{3}{2} p_{m}\left[\psi_{f} i_{q}+\left(L_{d}-L_{q}\right) i_{d} i_{q}\right]
$$

where $u_{d}, u_{q}$ are the armature voltage of the $d$-axis and $q$-axis, $i_{d}, i_{q}$ are the armature current of the $d$-axis and $q$-axis, $L_{d}, L_{q}$ are the winding inductance of stator in $d$-axis and $q$-axis, $R$ is the winding resistance of stator, $\psi_{f}$ is the $\mathrm{PM}$ (permanent magnet) flux linkage; $p$ is the differential operator $d / d t ; p_{m}$ is the number of pole pairs of the rotor, and $\omega_{m}$ is the rotor electrical angular speed.

Motion equations of servo system are as follows [5]:

$$
\begin{gathered}
J \frac{d \omega_{m}}{d t}=T_{e}-V \omega_{m}+T_{L}, \\
\omega_{m}=\frac{d \theta_{m}}{d t},
\end{gathered}
$$

where $J$ is the rotary inertia of the system, $T_{e}$ is the electromagnetism torque (i.e., driving torque), $V$ is the viscous friction coefficient of the rotor, and $T_{L}$ is the load torque.

Let $T_{d}$ be the disturbance torque which is an unknown value estimated by the disturbance observer. Then $T_{d}$ can be expressed as

$$
T_{d}=-V \omega_{m}+T_{L}
$$

In one sampling period, $T_{d}$ may be regarded as a constant, because the sampling frequency is much quicker than the variation of the disturbance torque in radar servo system. Hence, we have

$$
\frac{d T_{d}}{d t}=0
$$

From (3)-(5) the state equations can be got as

$$
\begin{gathered}
\dot{\mathbf{x}}=\mathbf{A x}+\mathbf{B} u, \\
\mathbf{y}=\mathbf{C} \mathbf{x},
\end{gathered}
$$

where $\mathbf{x}=\left[\begin{array}{c}\omega_{m} \\ T_{d}\end{array}\right], \mathbf{A}=\left[\begin{array}{cc}0 & 1 / J \\ 0 & 0\end{array}\right], \mathbf{B}=\left[\begin{array}{c}1 / J \\ 0\end{array}\right], \mathbf{C}=\left[\begin{array}{l}1 \\ 0\end{array}\right]$, and $u=T_{e}$.

For a PMSM with nonsalient pole structure, the $d q$-axis inductances are equal; that is, $L_{d}=L q=L$. The load rotary inertia and torque are identified online based on the field orientation control (FOC) system, where $i_{d}$ is controlled to be zero. The identification methods run in parallel with the vector control system. The block diagram of the whole system is shown in Figure 1.

\section{Identification of Radar Load Rotary Inertia Based on DOB}

3.1. Design of the DOB. Based on the state equations (6), the state observer with minimum order can be designed, where $\widehat{T}_{d}$ is the estimated value of the disturbance torque $T_{d}[6]$ :

$$
\begin{gathered}
\frac{d z}{d t}=-\lambda z+\lambda J_{n} \omega_{m}+u, \\
\widehat{T}_{d}=-\lambda z+\lambda J_{n} \omega_{m},
\end{gathered}
$$

where $J_{n}$ is the rotary inertia which is a constant, $z$ is the intermediate variable, and $-\lambda$ is the pole of the observer $(\lambda>$ $0)$.

Applying Laplace transformation to both sides of (7) and (8), respectively, we can get

$$
\begin{gathered}
s z(s)=-\lambda z(s)+\lambda J_{n} \omega_{m}(s)+u(s) \\
\Longrightarrow z(s)=\frac{\lambda J_{n} \omega_{m}(s)+u(s)}{s+\lambda} \\
\widehat{T}_{d}(s)=-\lambda z(s)+\lambda J_{n} \omega_{m}(s) \\
=\frac{-\lambda^{2} J_{n} \omega_{m}(s)-\lambda u(s)}{s+\lambda}+\lambda J_{n} \omega_{m}(s) \\
=\frac{s \lambda}{s+\lambda} J_{n} \omega_{m}(s)-\frac{-\lambda}{s+\lambda} u(s) .
\end{gathered}
$$

In order to simplify (10), introducing two intermediate variables $p_{1}(s)=\lambda \omega(s) /(s+\lambda)$ and $p_{2}(s)=\lambda u(s) /(s+\lambda)$ into (10), we have

$$
\widehat{T}_{d}(s)=J_{n} s p_{1}(s)-p_{2}(s) .
$$

Applying inverse Laplace transformation, we get

$$
\begin{array}{cc}
\frac{d p_{1}}{d t}=-\lambda p_{1}+\lambda u, & p_{1}(0)=0, \\
\frac{d p_{2}}{d t}=-\lambda p_{2}+\lambda \omega_{m}, & p_{2}(0)=0, \\
\widehat{T}_{d}(t)=J_{n} \widehat{p}_{2}-p_{1}, & \widehat{T}_{d}(0)=0 .
\end{array}
$$




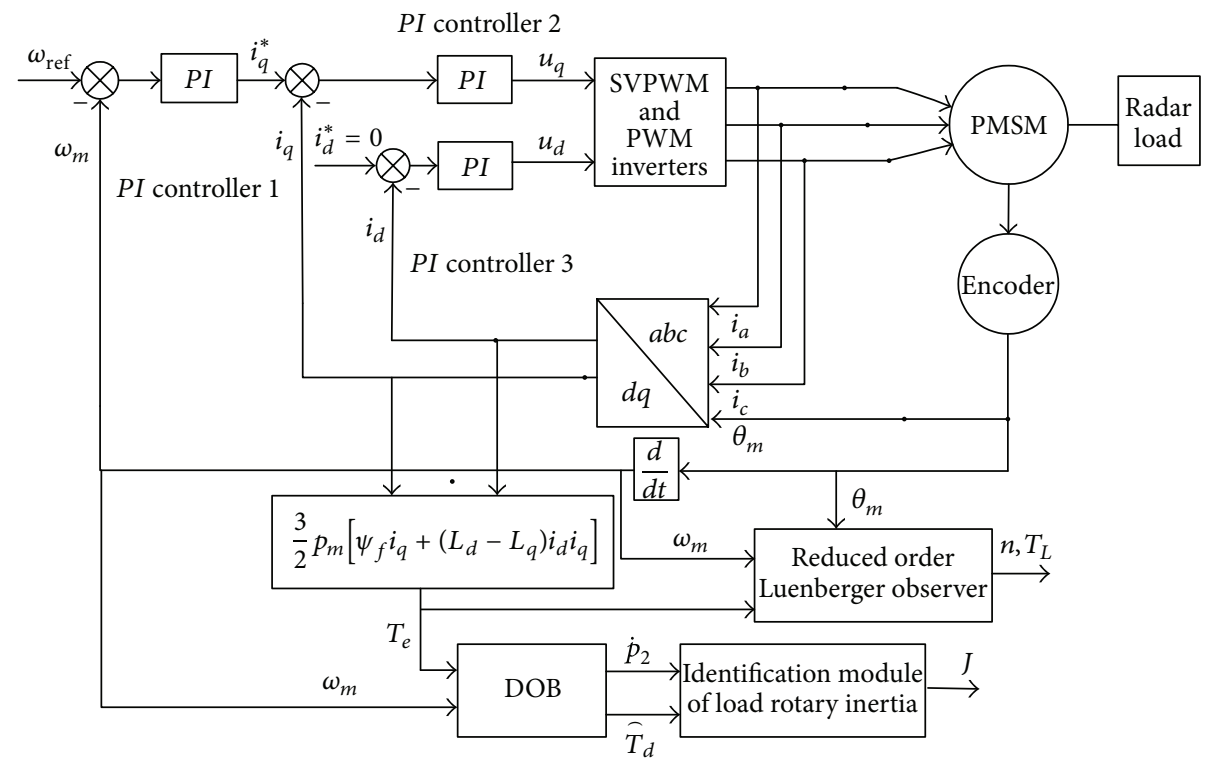

FIGURE 1: Block diagram of the load rotary inertia and torque identification.

3.2. Identification of Rotary Inertia Based on DOB. The rotary inertia can be expressed as

$$
\delta J=J-J_{n}
$$

where $J$ is the real rotary inertia, $J_{n}$ is the rotary inertia, and $\delta J$ is the rotary inertia caused by load variation or error.

From (3), (7), (8), and (15), we can get the following differential equation:

$$
\frac{d \widehat{T}_{d}}{d t}=-\lambda \widehat{T}_{d}-\lambda\left(\delta J \dot{\omega}_{m}+V \omega_{m}-T_{L}\right) .
$$

Applying Laplace transformation to (16), we get

$$
\begin{gathered}
s \widehat{T}_{d}(s)=-\lambda \widehat{T}_{d}(s)-\lambda \delta J s \omega_{m}(s)-\lambda V \omega_{m}(s)+\lambda T_{L}(s) \\
\Longrightarrow \widehat{T}_{d}(s)=-\delta J \frac{\lambda \omega_{m}(s)}{s+\lambda} s-V \frac{\lambda \omega_{m}(s)}{s+\lambda}+\frac{\lambda}{s+\lambda} T_{L}(s) .
\end{gathered}
$$

In order to simplify (17), introducing two intermediate variables $p_{2}(s)$ and $p_{3}(s)=\lambda /(s+\lambda)$ into (17) and applying inverse Laplace transformation, we have

$$
\begin{gathered}
\frac{d p_{3}}{d t}=-\lambda p_{3}+\lambda, \quad p_{3}(0)=0, \\
\widehat{T}_{d}(t)=-\delta J \dot{p}_{2}(t)-V p_{2}(t)+T_{L} p_{3}(t),
\end{gathered}
$$

where $\delta J \dot{q}_{1}(t)$ is the torque fluctuation caused by the variation of the rotary inertia, $V q_{1}(t)$ is the torque generated by friction, and $T_{L} q_{2}(t)$ is the constant torque.

Multiplying both sides of (15) by $\dot{q}_{1}(t)$, we can obtain

$$
\dot{p}_{2}(t) \widehat{T}_{d}(t)=-\delta J \dot{p}_{2}^{2}(t)-V \dot{p}_{2}(t) p_{2}(t)+T_{L} \dot{p}_{2}(t) p_{3}(t)
$$

Therefore, it is not difficult to prove that $p_{2}(t)$ is orthogonal to $\dot{p}_{2}(t)$ and that $p_{3}(t)$ is orthogonal to $\dot{p}_{2}(t)$.
Proof. When radar servo system is in steady state, the angular velocity $\omega(t)$ is the periodic signal, and so $\lim _{t \rightarrow+\infty}[\omega(t)-$ $\omega(t-T)]=0$. From (13), because $\omega(t)$ is the input of $p_{2}(t)$, $p_{2}(t)$ is also the periodic signal, and so $\lim _{t \rightarrow+\infty}\left[p_{2}(t)-p_{2}(t-\right.$ $T)]=0$ :

$$
\lim _{k \rightarrow+\infty} \int_{(k-1) T}^{k T} p_{2}(t) \dot{p}_{2}(t) d t=0,
$$

$$
\begin{aligned}
& \lim _{k \rightarrow+\infty} \int_{(k-1) T}^{k T} p_{2}(t) \dot{p}_{2}(t) d t \\
& =\lim _{k \rightarrow+\infty} \frac{p_{2}^{2}(k T)-p_{2}^{2}((k-1) T)}{2} \\
& =\lim _{k \rightarrow+\infty}\left(\left(\left[p_{2}(k T)-p_{2}((k-1) T)\right]\right.\right. \\
& \left.\left.\quad \times\left[p_{2}(k T)+p_{2}((k-1) T)\right]\right) \times 2^{-1}\right) \\
& \stackrel{\text { From }(13): \lim _{k \rightarrow+\infty} p_{2}(k T)-p_{2}((k-1) T)=0}{\longrightarrow}
\end{aligned}
$$

$=0$,

$$
\lim _{k \rightarrow+\infty} \int_{(k-1) T}^{k T} p_{3}(t) \dot{p}_{2}(t) d t=0,
$$

$$
\begin{aligned}
& \lim _{k \rightarrow+\infty} \int_{(k-1) T}^{k T} p_{3}(t) \dot{p}_{2}(t) d t \\
& \quad=\lim _{k \rightarrow+\infty}\left\{\left.\left[p_{3}(t) p_{2}(t)\right]\right|_{(k-1) T} ^{k T}-\int_{(k-1) T}^{k T} \dot{p}_{3}(t) p_{2}(t) d t\right\} \\
& \stackrel{\text { From }(18): \lim _{t \rightarrow+\infty} p_{3}(t)=1 ; \lim _{t \rightarrow+\infty} \dot{p}_{3}(t)=0}{\longrightarrow}
\end{aligned}
$$

$=0$. 


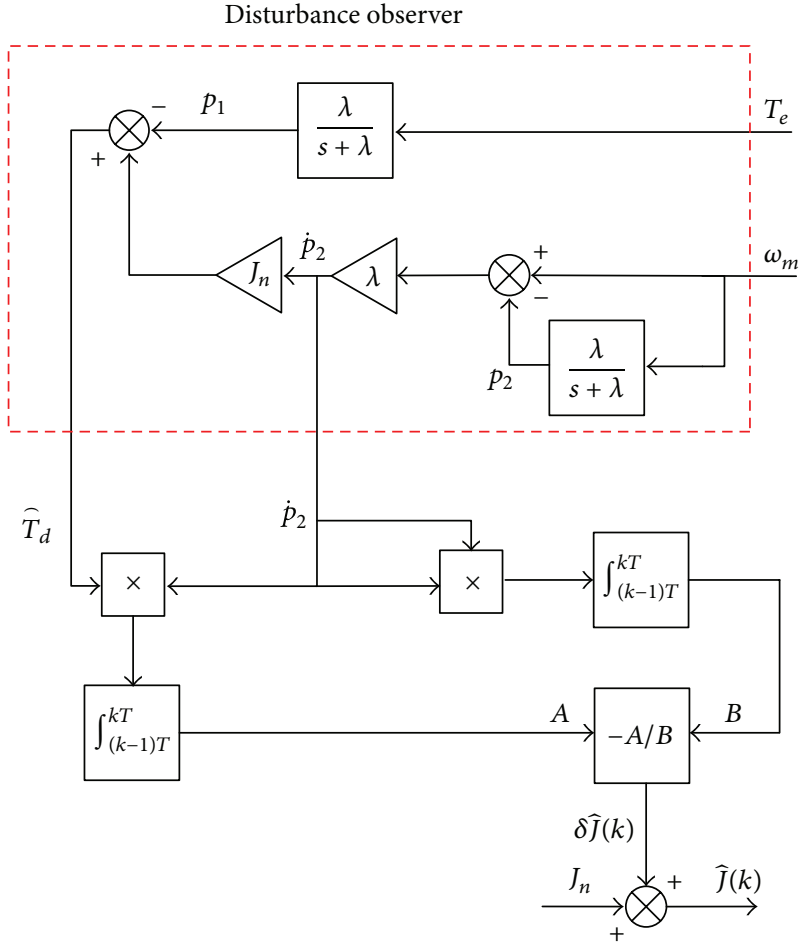

FIGURE 2: Block diagram of identification of the rotary inertia based on DOB.

Thus, the rotary inertia method based on DOB can be obtained. The two specific calculation steps are as follows.

(1) Use the orthogonality to estimate the variation value of the rotary inertia:

$$
\delta \widehat{J}(k)=\frac{\int_{(k-1) T}^{k T} \widehat{T}_{d}(t) \dot{p}_{2}(t) d t}{\int_{(k-1) T}^{k T} \dot{p}_{2}^{2}(t) d t}, \quad(k=1,2, \ldots) .
$$

(2) Add the present variation value of the estimated rotary inertia to the previous value of the rotary inertia and then get the new value of the estimated rotary inertia:

$$
\widehat{J}(k)=J_{n}+\delta \widehat{J}(k) .
$$

The overall identification process is shown in Figure 2.

\section{Observation of Load Torque and Speed Based on Reduced Order Luenberger Observer}

Transform the motion equations (3) into state-space equations:

$$
\left[\begin{array}{c}
\dot{\theta}_{m} \\
\dot{\omega}_{m}
\end{array}\right]=\left[\begin{array}{cc}
0 & 1 \\
0 & -\frac{V}{J}
\end{array}\right]\left[\begin{array}{c}
\theta_{m} \\
\omega_{m}
\end{array}\right]+\left[\begin{array}{c}
0 \\
\frac{1}{J}
\end{array}\right]\left(T_{e}-T_{L}\right) .
$$

Discretize the continuous system equation (3); then, we can get the discretized differential equation [12]:

$$
\left[\begin{array}{l}
\theta_{r}(k+1) \\
\omega_{r}(k+1)
\end{array}\right]=F\left[\begin{array}{l}
\theta_{r}(k) \\
\omega_{r}(k)
\end{array}\right]+H\left[T_{e}(k)-T_{L}(k)\right],
$$

where

$$
\begin{gathered}
F=e^{A T_{s}}=\left[\begin{array}{cc}
1 & \frac{J}{f}(1-\lambda) \\
0 & \lambda
\end{array}\right]=\left[\begin{array}{ll}
1 & F_{12} \\
0 & F_{22}
\end{array}\right], \\
H=\int_{0}^{T_{s}} e^{A t} B d t=\left[\begin{array}{c}
\frac{1}{f}\left[T_{s}-\frac{J}{f}(1-\lambda)\right] \\
\frac{1}{f}(1-\lambda)
\end{array}\right]=\left[\begin{array}{l}
H_{1} \\
H_{2}
\end{array}\right],
\end{gathered}
$$

where $\lambda=e^{\left(-(f / J) T_{s}\right)}$ and $T_{s}$ is the sampling time of the system.

Since the variation of the load torque is much slower compared to that of the sampling time, the load torque can be regarded as a constant in the sampling time interval; that is,

$$
T_{L}(k+1)=T_{L}(k) .
$$

From (26)-(27), we can get

$$
\left[\begin{array}{c}
\theta_{r}(k+1) \\
\omega_{r}(k+1) \\
T_{L}(k+1)
\end{array}\right]=M\left[\begin{array}{c}
\theta_{r}(k) \\
\omega_{r}(k) \\
T_{L}(k)
\end{array}\right]+N u,
$$

where

$$
M=\left[\begin{array}{ccc}
1 & F_{12} & -H_{1} \\
0 & F_{22} & -H_{2} \\
0 & 0 & 1
\end{array}\right], \quad N=\left[\begin{array}{c}
H_{1} \\
H_{2} \\
0
\end{array}\right], \quad u=T_{e} .
$$

Because radar servo system is a position control, the position can be obtained by position encoder and is known, while the speed and load torque are estimated and are unknown. Thus, the terms regarding position can be deleted in (28) and then the reduced order load torque observer can be obtained:

$$
\begin{gathered}
{\left[\begin{array}{l}
x_{1}(k+1) \\
x_{2}(k+1)
\end{array}\right]=\left[\begin{array}{ll}
M_{11} & M_{12} \\
M_{21} & M_{22}
\end{array}\right]\left[\begin{array}{l}
x_{1}(k) \\
x_{2}(k)
\end{array}\right]+\left[\begin{array}{l}
N_{1} \\
N_{2}
\end{array}\right] u} \\
y(k)=\left[\begin{array}{ll}
I & 0
\end{array}\right]\left[\begin{array}{l}
x_{1}(k) \\
x_{2}(k)
\end{array}\right] .
\end{gathered}
$$

In $(30)$

$$
\begin{gathered}
x_{1}(k)=\theta_{m}(k), \quad x_{2}(k)=\left[\begin{array}{c}
\omega_{m}(k) \\
T_{L}(k)
\end{array}\right], \quad M_{11}=1, \\
M_{12}=\left[\begin{array}{ll}
F_{12} & -H_{1}
\end{array}\right], \quad M_{21}=\left[\begin{array}{l}
0 \\
0
\end{array}\right], \\
M_{22}=\left[\begin{array}{cc}
F_{22} & -H_{2} \\
0 & 1
\end{array}\right], \quad N_{1}=H_{1}, \quad N_{2}=\left[\begin{array}{c}
H_{2} \\
0
\end{array}\right] .
\end{gathered}
$$


Also, $x_{1}$ is the observable state variable and $x_{2}$ is the unobservable state variable.

From (30) we can further get

$$
\begin{gathered}
y(k+1)=x_{1}(k+1)=M_{11} x_{1}(k)+M_{12} x_{2}(k)+N_{1} u \\
x_{2}(k+1)=M_{21} y(k)+M_{22} x_{2}(k)+N_{2} u .
\end{gathered}
$$

Now, let $\bar{u}=M_{21} y(k)+N_{2} u$ and let $w(k)=M_{12} x_{2}(k)=y(k+$ 1) $-M_{11} x_{1}(k)-N_{1} u$, and the state equation of the reduced order system can be obtained:

$$
\begin{gathered}
x_{2}(k+1)=M_{22} x_{2}(k)+\bar{u}, \\
w(k)=M_{12} x_{2}(k) .
\end{gathered}
$$

According to (33), the reduced order observer of the load torque can be constructed:

$$
\begin{aligned}
\hat{x}_{2}(k+1)= & M_{22} \hat{x}_{2}(k)+\bar{u}+l\left[w(k)-M_{12} \widehat{x}_{2}(k)\right] \\
= & \left(M_{22}-l M_{12}\right) \hat{x}_{2}(k)+M_{21} y(k)+N_{2} u \\
& +l\left(y(k+1)-M_{11} x_{1}(k)-N_{1} u\right) .
\end{aligned}
$$

Equation (34) includes the term $y(k+1)$ which cannot be obtained directly. Moreover, $y(k+1)$ and $y(k)$ can play the role of differential which can amplify the position measurement error. Hence, an intermediate variable $z$ is introduced:

$$
z(k)=x_{2}(k)-l y(k) .
$$

Substituting (35) into (36), the term $y(k+1)$ can be cancelled:

$$
\begin{aligned}
z(k+1)= & \left(M_{22}-l M_{12}\right) z(k) \\
& +\left[\left(M_{22}-l M_{12}\right) l+M_{21}\right] y(k) \\
& +N_{2} u+l\left(-M_{11} x_{1}(k)-N_{1} u\right) .
\end{aligned}
$$

Then, the estimated state variable can be restored by (35) as

$$
\widehat{x}_{2}(k)=z(k)+l y(k)
$$

where $l=\left[\begin{array}{l}l_{1} \\ l_{2}\end{array}\right]$. In order to get the feedback gain coefficients $l_{1}$ and $l_{2}$, the poles of the desired observer are supposed to be $p_{1}$ and $p_{2}$, where the two poles are equal (i.e., $p_{1}=p_{2}=P$ ) and the characteristic polynomial of the observer is $\mid z I-\left(M_{22}-\right.$ $\left.l M_{12}\right) \mid$. Then, we have

$$
\left|z I-\left(M_{22}-l M_{12}\right)\right|=(z-p)^{2} .
$$

Let the two sides of (38) be identically equal; then, the feedback gain coefficients $l_{1}$ and $l_{2}$ can be got:

$$
\begin{gathered}
l_{1}=\frac{H_{2}\left(-2 p+1+F_{22}\right)}{H_{1}-F_{22} H_{1}+F_{12} H_{2}}+\frac{H_{1}\left(F_{22}-p\right)^{2}}{F_{12}\left(H_{1}-F_{22} H_{1}+F_{12} H_{2}\right)}, \\
l_{2}=\frac{-(p-1)^{2}}{H_{1}-F_{22} H_{1}+F_{12} H_{2}} .
\end{gathered}
$$

TABLE 1: PMSM parameters and PI.

\begin{tabular}{lc}
\hline Rated power & $1.5 \mathrm{~kW}$ \\
Rated torque & $7.5 \mathrm{~N} \cdot \mathrm{m}$ \\
Rated speed & $3000 \mathrm{r} / \mathrm{min}$ \\
Rated current & $6 \mathrm{~A}$ \\
Winding resistance of stator & $R=2.23 \Omega$ \\
$d, q$-axis inductance & $L_{d}=L_{q}=22.5 \mathrm{mH}$ \\
PM flux linkage & $\Psi_{f}=0.2865 \mathrm{~Wb}$ \\
Combined inertia & $J=0.01087 \mathrm{~kg} \cdot \mathrm{m}^{2}$ \\
Rotor viscous friction coefficient & $V=0.004 \mathrm{~N} \cdot \mathrm{m} \cdot\left(\mathrm{rad} \cdot \mathrm{s}^{-1}\right)^{-1}$ \\
Number of pole pairs & $p_{m}=3$ \\
$P I$ controller 1 & $P=150 \quad I=20$ \\
$P I$ controller 2 & $P=1.8 \quad I=0.015$ \\
$P I$ controller 3 & $P=2.0 \quad I=0.018$ \\
\hline
\end{tabular}

In order to guarantee the stability of the system [13], the pole $p$ of the load torque observer should be within $0 \sim 1$ of the unit circle in the $z$-plane. When the pole $p$ is adjacent to 0 , the response of the load torque observer is faster but it is more sensitive to the input noise. Therefore, in order to reasonably choose the pole of the load torque observer, both the response speed of the load torque observer and the noise rejection ability should be taken into consideration.

\section{Simulation Model of the Parameter Identification System}

The PMSM parameters adopted in the simulation are listed in Table 1 . The parameters $P$ and $I$ of three $P I$ controllers are shown in Table 1.

5.1. Simulation Model of the Identification of Load Rotary Inertia. The simulation model of the disturbance torque observer can be established according to (12)-(14). In MatLab/s-function, the program of online identification of rotary inertia can be written. The overall simulation model of online identification of rotary inertia is shown in Figure 3.

5.2. Simulation Model of Load Torque Observer. The reduced order Luenberger load torque observer consists of differential equations. The iteration algorithm can be programmed in MatLab/s-function according to (35). In the iteration algorithm, the sampling time is set to be $1 \mathrm{~ms}$ and the pole of the observer is set to be 0.65 . The overall simulation model is shown in Figure 4.

\section{Simulation Results and Analysis}

6.1. Simulation Results of the Identification of Rotary Inertia. In the simulation model of the online identification of rotary inertia based on DOB, the test signal of the speed command is set to be a sine signal with the magnitude $50 \mathrm{rpm}$ and the period $100 \mathrm{hz}$. Overlapping the command test signal onto the speed command signal and identifying the rotary inertia online, the identification results are shown in Figure 5. 


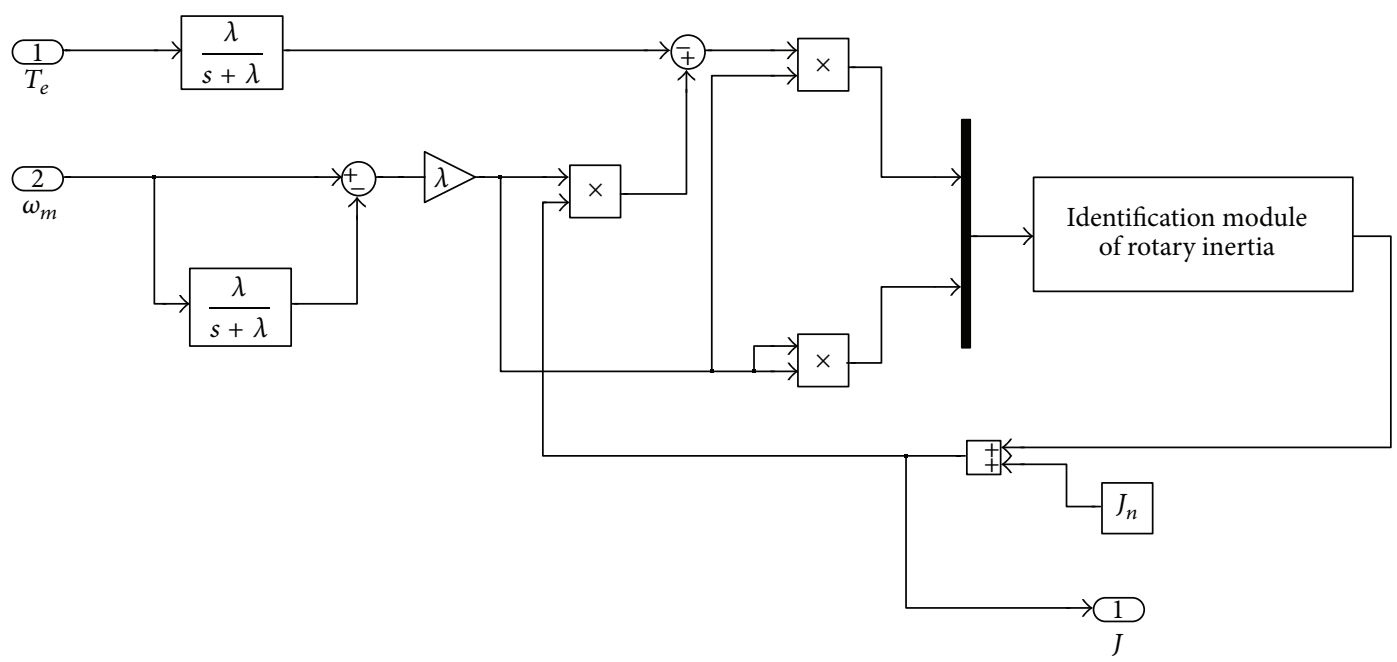

FIGURE 3: Simulation model of online identification of rotary inertia based on DOB.

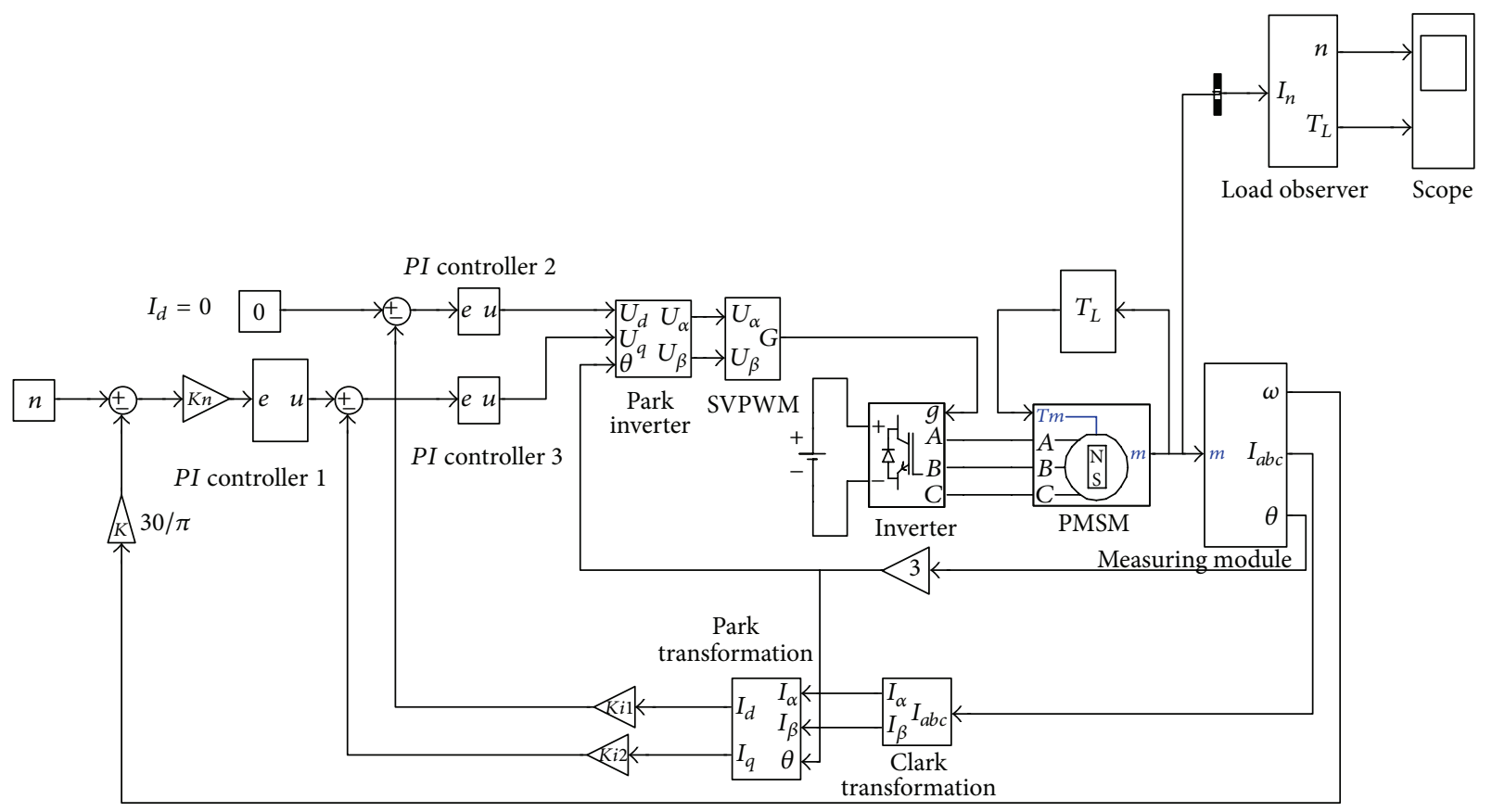

FIgURE 4: Simulation model of the load torque observer.

Here, the real value of the rotary inertia of the system is $0.01087 \mathrm{~kg} \cdot \mathrm{m}^{2}$ and the identified value is $0.01077 \mathrm{~kg} \cdot \mathrm{m}^{2}$. From the simulation results, it can be seen that the precision of the identification method of load rotary inertia is high and the speed is fast.

6.2. Simulation Results of Load Torque Observer. During the simulation of the load torque observer, the sampling frequency of the reduced order load torque observer is set to be $5000 \mathrm{HZ}$, the pole of the observer is configured to be 0.8 , and the speed command is set to be $50 \mathrm{rpm}$. In order to study the tracking ability of the reduced order load torque observer to the variation of the load torque, the load torque disturbance is set to be a step signal variation and a sine signal variation, respectively. The tracking curves of the load torque observer to the load torque are shown in Figures 6 and 7.

In Figure 6, when $t=0.1 \mathrm{~s}$, the given load torque is $1 \mathrm{Nm}$, when $t=0.3 \mathrm{~s}$, the given load torque is $2 \mathrm{Nm}$, when $t=0.5 \mathrm{~s}$, the given load torque reduces to $1 \mathrm{Nm}$, and when $t=0.7 \mathrm{~s}$, the given load torque reduces to $1 \mathrm{Nm}$ once again.

From Figure 7, the frequency of the given sine load torque is $100 \mathrm{rad} / \mathrm{s}$ and the magnitude is $3 \mathrm{Nm}$. From the tracking curves of the step signal and the sine signal it can be seen that the designed reduced order load torque observer can quickly and accurately track the variation of the load torque, which provides accurate compensation information to the load 


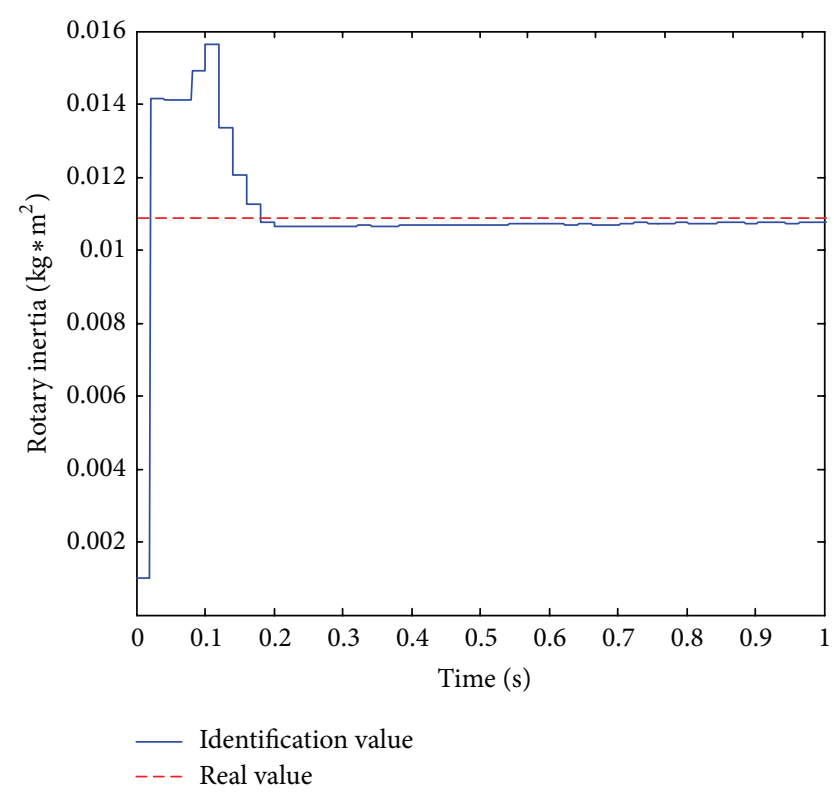

Figure 5: Curves of the identification of rotary inertia.

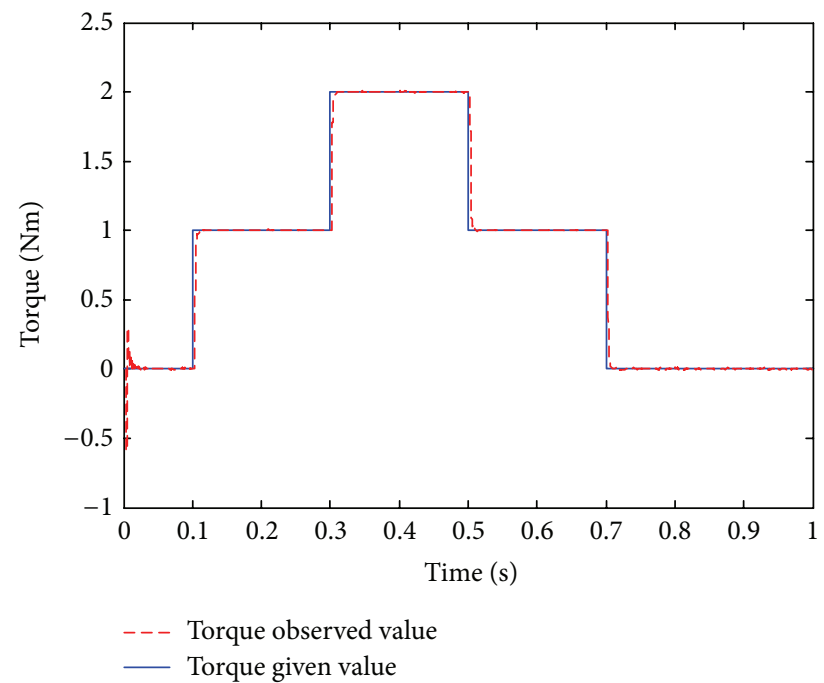

FIgURE 6: Tracking cures of the load torque (step signal variation).

compensation controller and makes the system have better disturbance rejection ability.

6.3. Simulation Results of Load Speed Observer. In order to study the observation ability of the designed load torque observer on speed, we add some white noise to the collected position signal in the simulation model and compare the speed curve obtained by the traditional differential with that estimated by the load torque observer. The speed is set to be $50 \mathrm{rpm}$ and the load is still given by sine signal. The simulation results are shown in Figure 8. Figure 8(a) shows the speed calculated by the direct differential and Figure $8(\mathrm{~b})$ is the speed estimated by load torque observer. From Figure 7 it can be seen that under the same noise disturbance the

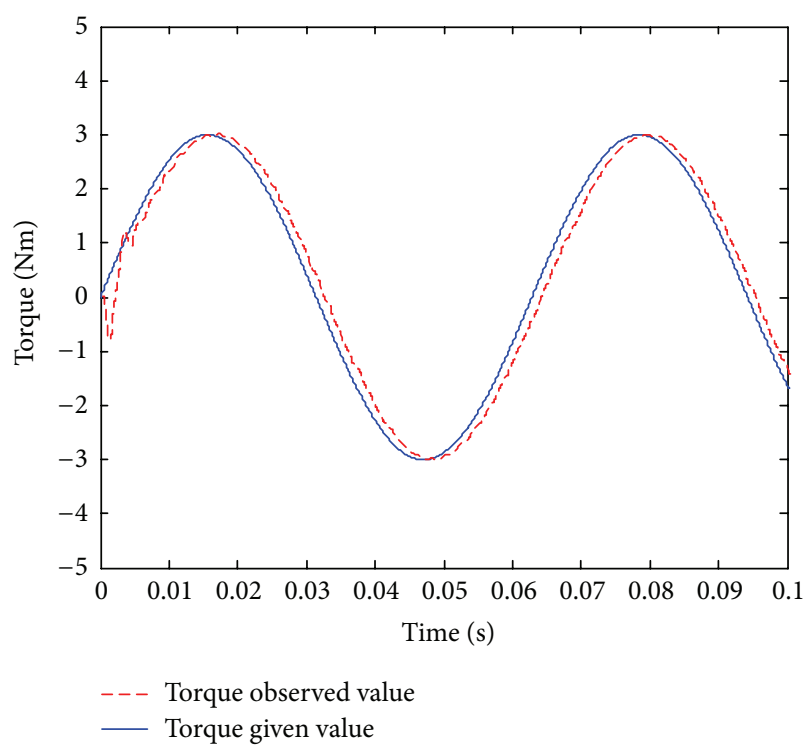

FIGURE 7: Tracking cures of the load torque (sine signal variation).

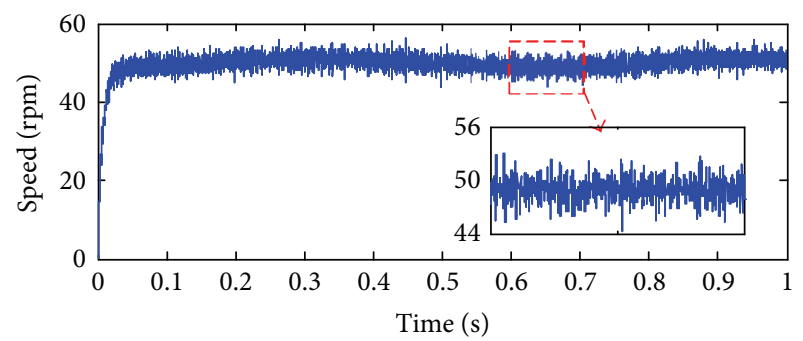

(a)

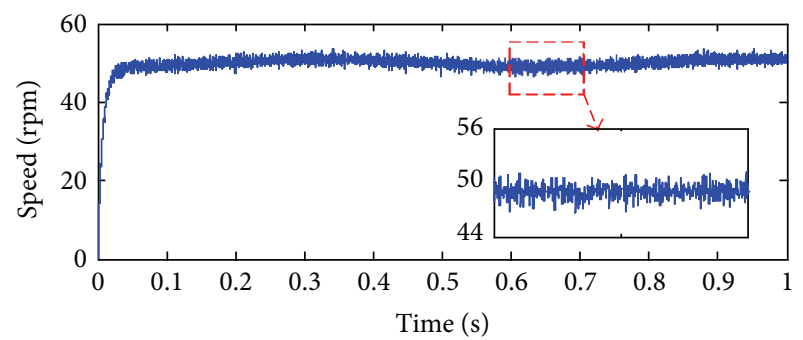

(b)

FIGURE 8: Speed tracking curves: (a) speed calculated by the direct differential and (b) speed estimated by the load torque observer.

speed curve estimated by the load torque observer is much smoother than that calculated by the direct differential. Since the load torque observer can suppress position noise signal, it can obtain more accurate speed values.

\section{Conclusions}

This paper presents online identification methods of load rotary inertia, load torque, and speed in radar servo system, respectively. First, the identification algorithm of load rotary inertia based on DOB is described. This algorithm can fast and accurately identify the load rotary inertia, which provides 
accurate and reliable rotary inertia values to parameter selfadjusting algorithm and other advanced control algorithms. Then, a reduced order Luenberger load torque observer is designed to accurately observe the variation of the load torque online. The designed torque observer provides accurate estimated torque to compensate for the load disturbance and thus enhances the disturbance rejection ability of the system. In addition, the designed torque observer can also estimate the speed value and overcome the amplification of the position noise error generated by the direct differential algorithm. Finally, the simulation models are established to verify the proposed online identification method of PMSM parameters. The simulation results illustrate the practicability and feasibility of the proposed identification method of rotary inertia and the proposed reduced order load torque observer. The proposed methods in this paper provide a solid theoretical basis for the experiments and practical application in the future.

\section{Conflict of Interests}

The authors declare that there is no conflict of interests regarding the publication of this paper.

\section{Acknowledgments}

This research was supported by the National Natural Science Foundation of China (no. 61305104) and the Scientific and Technical Supporting Programs of Sichuan Province (no. 2013GZX0152 and no. 2013GZ0054).

\section{References}

[1] S. Li and Z. Liu, "Adaptive speed control for permanent-magnet synchronous motor system with variations of load inertia," IEEE Transactions on Industrial Electronics, vol. 56, no. 8, pp. 30503059, 2009.

[2] Y. Gao and $\mathrm{D}$. Xu, "Adaptive load torque observer using hyperstability for PMSM servo system," High Technology Letters, vol. 11, no. 4, pp. 387-391, 2005.

[3] J. C. G. Rodrigues, Â. J. J. Rezek, M. L. B. Martinez, D. F. Bernardes, and N. D. O. Júnior, "Implementation of a simulator for the most commonly found industrial motor loads based on pulse-width modulation inverters and torque estimator," Electric Power Components and Systems, vol. 41, no. 3, pp. 345364, 2013.

[4] K. Fujita and K. Sado, "Instantaneous speed detection with parameter identification for AC servo systems," IEEE Transactions on Industry Applications, vol. 28, no. 4, pp. 864-872, 1992.

[5] A. Wang, W. Xu, and C.-T. Liu, "On-line PI self-turning based on inertia identification for permanent magnet synchronous motor servo system," in Proceedings of the International Conference on Power Electronics and Drive Systems (PEDS '09), pp. 1406-1410, 2009.

[6] I. Awaya, Y. Kato, I. Miyake, and M. Ito, "New motion control with inertia identification function using disturbance observer," in Proceedings of the International Conference on Power Electronics and Motion Control, vol. 1, pp. 77-81, San Diego, Calif, USA, 1992.
[7] W.-S. Huang, C.-W. Liu, P.-L. Hsu, and S.-S. Yeh, "Precision control and compensation of servomotors and machine tools via the disturbance observer," IEEE Transactions on Industrial Electronics, vol. 57, no. 1, pp. 420-429, 2010.

[8] K. Zawirski, D. Janiszewski, and R. Muszynski, "Unscented and extended Kalman filters study for sensorless control of PM synchronous motors with load torque estimation," Bulletin of the Polish Academy of Sciences: Technical Sciences, vol. 61, no. 4, pp. 793-801, 2013.

[9] D. Janiszewski, "Load torque estimation for sensorless PMSM drive with output filter fed by PWM converter," in Proceedings of the 39th Annual Conference of the IEEE Industrial Electronics Society (IECON '13), pp. 2953-2959, Vienna, Austria, November 2013.

[10] F. Andoh, "Moment of inertia identification using the time average of the product of torque reference input and motor position," IEEE Transactions on Power Electronics, vol. 22, no. 6, pp. 2534-2542, 2007.

[11] D. Grignion, X. Chen, N. Kar, and H. Qian, "Estimation of load disturbance torque for DC motor drive systems under robustness and sensitivity consideration," IEEE Transactions on Industrial Electronics, vol. 61, no. 2, pp. 930-942, 2014.

[12] V. Q. Leu, H. H. Choi, and J.-W. Jung, "Fuzzy sliding mode speed controller for PM synchronous motors with a load torque observer," IEEE Transactions on Power Electronics, vol. 27, no. 3, pp. 1530-1539, 2012.

[13] K.-B. Lee and F. Blaabjerg, "Robust and stable disturbance observer of servo system for low-speed operation," IEEE Transactions on Industry Applications, vol. 43, no. 3, pp. 627-635, 2007. 


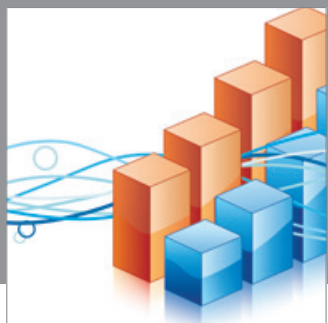

Advances in

Operations Research

mansans

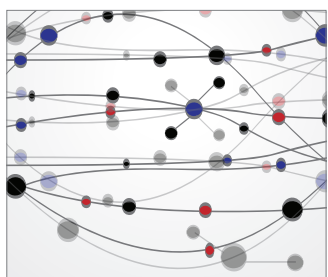

The Scientific World Journal
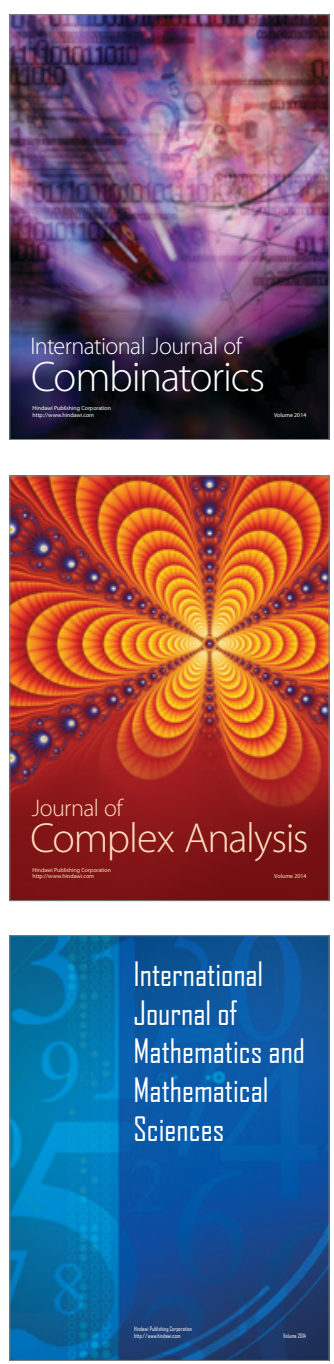
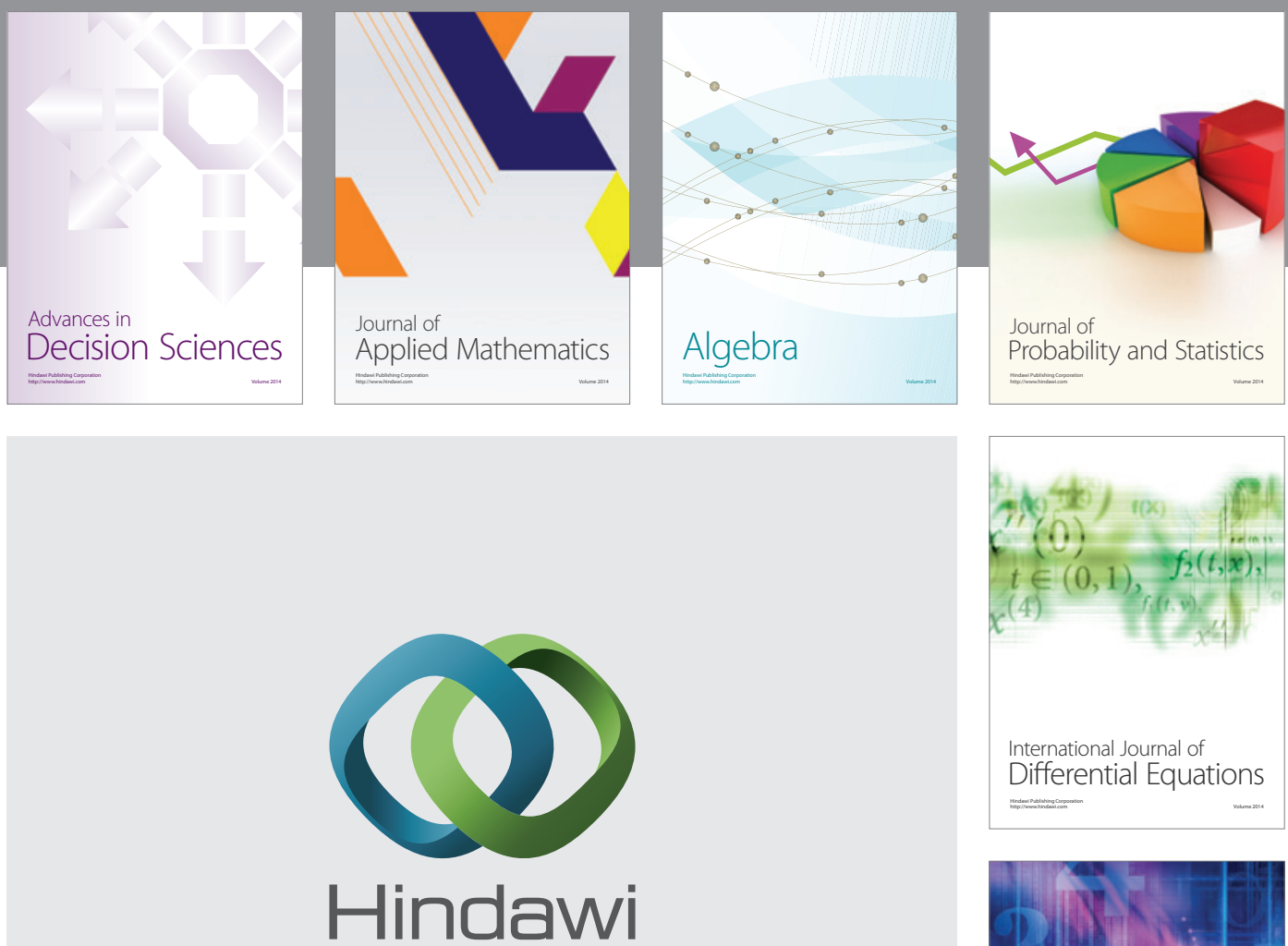

Submit your manuscripts at http://www.hindawi.com
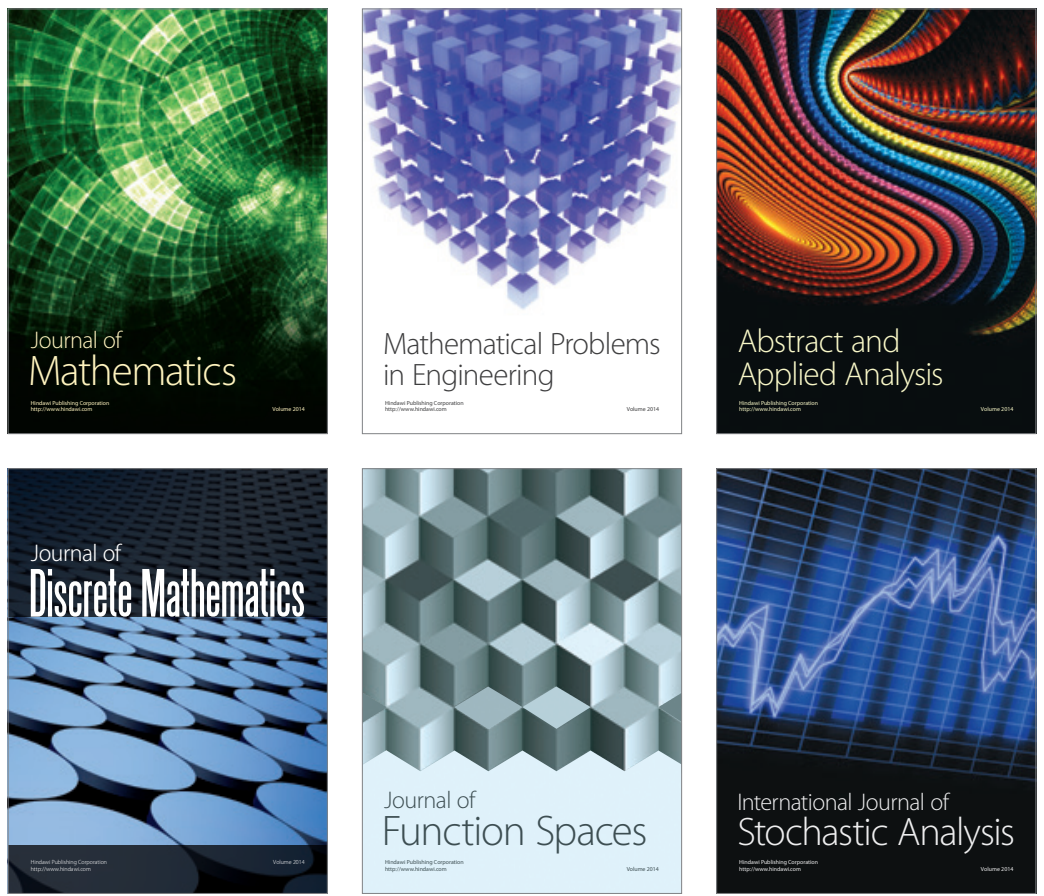

Journal of

Function Spaces

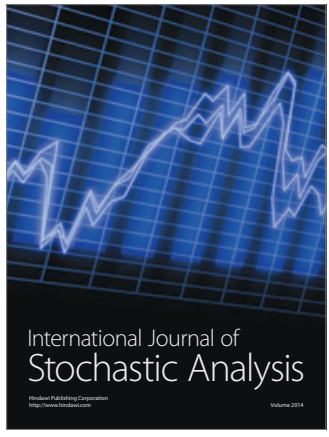

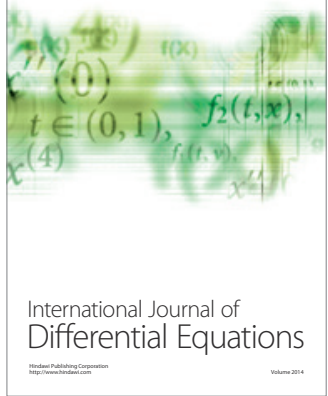
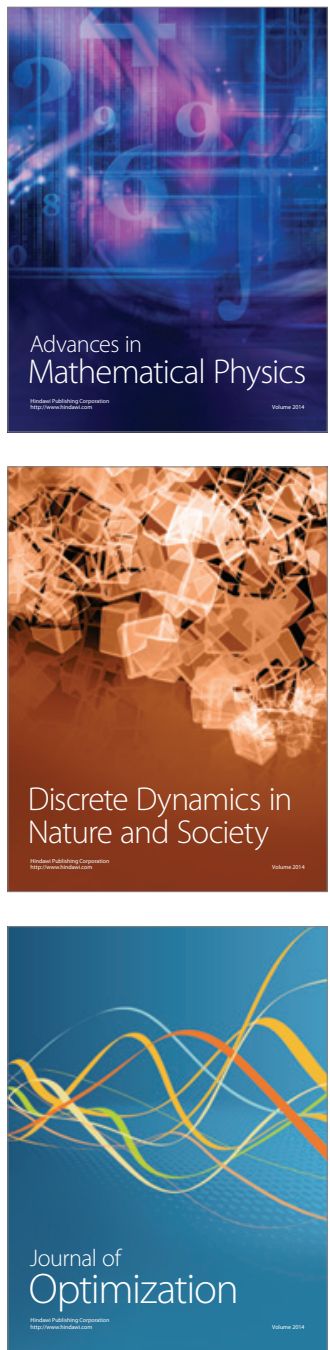